\title{
Discrepancies in cigarette brand sales and adult market share: are new teen smokers filling the gap?
}

\author{
K Michael Cummings, Andrew Hyland, Eugene Lewit, Don Shopland
}

Department of Cancer Control and Epidemiology, Roswell Park Cancer Institute, Buffalo, New York, USA $\mathrm{KM}$ Cummings A Hyland

Center for the Future of Children, Los Altos, California

E Lewit

Smoking and Tobacco Control Program,

National Cancer Institute, Rockville, Maryland

D Shopland

Correspondence to: Dr K Michael Cummings, Department of Cancer Department of Cancer Roswell Park Cancer Roswell Park Cancer Institute, Elm and Cariton Streets, Buffalo, New 14263, USA; em sc3102.med.buffalo.edu
Abstract

Objective-To examine the extent and type of cigarette brand switching by adult smokers. To evaluate discrepancies between actual and projected cigarette brand sales based on changes in adult smoking patterns.

Design-Data analysed come from a cohort tracking survey of 11966 cigarette smokers aged 25-64 years from 20 communities in the United States who were followed between 1988 and 1993 as part of the National Cancer Institute's Community Intervention Trial for Smoking Cessation.

Outcome measures-Respondents were asked about their current cigarette brand in 1988 and 1993. Brand switching was inferred when a smoker reported a different cigarette brand in 1988 and 1993. Company switching was defined as brand switching for whom a different parent company was identified for the 1993 brand compared with the brand used in 1988 . A ratio measure was computed to reflect gains in market share from brand switching and losses from brand switching, quitting, and death, for specific cigarette brands, between 1988 and 1993. This ratio measure was used to estimate the projected unit sales for top-selling premium brands in 1993 and was compared with actual unit sales for the same year.

Results-We estimate that an average of $\mathbf{9 . 5 \%}$ of smokers switched cigarettes brands and $7.6 \%$ switched companies each year. Most of those who did switch cigarette brands changed from a premium brand to a discount or generic brand. Between 1988 and 1993, top-selling premium brands such as Marlboro, Camel, and Newport, lost about four times as many adult smokers as they gained. Whereas premium brand cigarettes lost some smokers to discount and generic cigarettes, over $50 \%$ of losses were due to smokers quitting or dying. Actual unit sales were substantially higher than projected sales (based on adult market share) for Marlboro and Camel, but not for other brands.

Conclusions-Most smokers are brand loyal. Price seems to be an important factor motivating brand switching among adult smokers. It appears that recruit- ment of new customers among the ranks of non-smokers is necessary for premium cigarette brands such as Marlboro and Camel to maintain sales comparable to previous years.

(Tobacco Control 1997;6 (suppl 2):S38-S43)

Keywords: brand preferences; cigarette smoking behaviour

\section{Introduction}

Cigarettes are among the most heavily advertised consumer products in America. In 1993 , cigarettes makers spent $\$ 6.03$ billion on advertising and promotions.'

There has been much dispute about the effect of cigarette advertising on smoking behaviour, particularly in regards to young people. $^{2}$ Some groups have accused the cigarette industry of using advertising and promotions to encourage youngsters to try smoking. ${ }^{3-7}$ Cigarette makers, however, insist that their marketing efforts do not target teenagers intentionally. Rather, they argue that cigarette advertising and promotions are intended to affect interbrand competition among adults who already smoke. ${ }^{89}$

Despite these assertions by the tobacco industry, it is generally held that the purpose of advertising for any product is to increase consumer demand for that particular product. In the case of branded products such as cigarettes, advertising and promotion may affect demand by maintaining brand purchases by those who might otherwise switch brands or quit smoking and by encouraging initiation of brand purchases by current smokers switching from other brands, by former smokers returning to the market, and by new smokers. To date, studies of the effect of cigarette advertising have not attempted to measure separately the effects of advertising on brand retention, brand switching, relapse among former smokers and initiation of smoking among young smokers. It has been noted, however, that because, in the American market, 2-2.5 million smokers die or stop smoking annually, the industry as a whole has a strong incentive to recruit new smokers and individual tobacco companies face similarly strong incentives to capture a healthy share of the starter's market for their brands. ${ }^{\circ}$

We do not directly address the effects of cigarette advertising on the recruitment of new 8 smokers here, but we analysed data collected as part of the National Cancer Institute's 흐 Community Intervention Trial for Smoking? 
Cessation (COMMIT) to examine cigarette brand loyalty and brand switching in a cohort of smokers followed over a five-year period. Five questions were used to guide the analyses.

- To what extent do adult smokers switch brands over a five-year period?

- To what brands are smokers switching?

- What is the effect of cigarette brand switching on the market share for different cigarette brands and manufacturers?

- Which characteristics of smokers are associated with brand switching (demographics, amount smoked daily, type of cigarette smoked, desire to stop smoking)?

- How closely do actual cigarette sales for top-selling brands compare with projected sales based upon the changing smoking habits of adult smokers?

\section{Methods \\ COMMIT STUDY \\ The data come from a longitudinal study involving 18332 cigarette smokers from 20 communities in the United States who were followed between 1988 and 1993 as part of the COMMIT study. The design and primary out- comes of the COMMIT study have been described previously. ${ }^{10-13}$ Briefly, the COM- MIT study was a randomised, controlled trial conducted at the community level to test the effectiveness of a multifaceted intervention to help smokers achieve and maintain cessation. The data adopted in this study involved 10 matched pairs of communities.}

\section{DATA COLLECTION}

From January to May 1988 a telephone survey was conducted to identify cohorts of approximately 915 current cigarette smokers aged 25-64 in each of the following communities: Bellingham and Longview/Kelso, Washington; Albany/Corvallis and Medford/ Ashland, Oregon; Vallejo and Hayward, California; Santa $\mathrm{Fe}$ and Las Cruces, New Mexico; Cedar Rapids and Davenport, Iowa; Raleigh and Greensboro, North Carolina; Paterson and Trenton, New Jersey; Lowell and Fitchburg/Leominster, Massachusetts; and Yonkers, New Rochelle, Utica, and Binghamton/Johnson City, New York.

The survey was conducted centrally using a modified, random-digit dialling technique and community-specific geographic screening to identify households within the targeted areas. The survey was implemented in two stages. The first stage involved identifying representative samples of approximately 5400 households within each community and gathering information on the age, gender, and smoking habits of all adults within selected households. In the second stage, a sample of current smokers aged 25-64 years was selected for an extended interview which included questions about current and past smoking habits, brand and type of cigarette usually smoked, interest in quitting smoking, and sociodemographic characteristics. Current smokers were defined as those who reported having smoked at least 100 cigarettes in their lifetime and who reported smoking at the time of interview.
The mean response rate for the household rostering portion of the survey was $82.8 \%$. Of the eligible smokers identified from the household rostering, $86.0 \%$ completed the extended interview. The initial cohort identification survey, gathered data on a total of 18332 current smokers aged 25-64 years who were then followed prospectively until 1993.

From 1989 until 1992, cohort participants were contacted once a year by telephone or mail to assess their current smoking status and residency. Between January and May 1993, cohort members were asked to respond to a 20-minute telephone interview, which included questions about current smoking status, efforts made to stop smoking over the preceding five years, and brand and type of cigarette currently smoked among those still smoking.

Overall, $65.3 \%$ of cohort members ( $\mathrm{n}=$ 11966 ) provided information on their smoking status at the final contact in 1993. Most of the cohort members who were classified as non-responders were those who could not be located $30.6 \%(n=5607)$; an additional $2.5 \%(n=463)$ were reported deceased, and $1.6 \%(n=296)$ refused to participate in the follow-up survey. Attrition was higher for younger, single, less educated members of the cohort. ${ }^{14}$

In the follow-up survey, $31 \%$ of cohort members $(n=3765)$ reported themselves to be non-smokers. Among the 8201 subjects who were still smoking in 1993, cigarette brand information was available for $7081(86.3 \%)$.

\section{MEASUREMENTS}

In both the 1988 and 1993 surveys, current smokers were asked to provide the six-digit UPC code listed on the side of their current pack of cigarettes. Respondents who did not have a pack available or who could not locate the UPC code on their pack were asked to give the name of the cigarette brand they usually smoke. We developed a list of 100 cigarette brands and their corresponding UPC codes so that each respondent's reported UPC code could be linked to a specific cigarette brand.

\section{Brand loyalty/switching}

Brand loyalty was inferred when a smoker reported smoking the same cigarette brand in both surveys. A change in the type of cigarette smoked within the same brand name was not considered a brand switch (Marlboro Regular and Marlboro Lights were considered to be the same brand). Brand switching was inferred when a smoker reported smoking a different cigarette brand in 1988 and 1993. Switching between different types of the same brand was not considered to be brand switching because the measure of brand choice was not specific enough to accomplish this.

\section{Gains vs losses}

A ratio measure was calculated to reflect gains or losses to specific brands between 1988 and 1993. A ratio of 1.0 for a brand would indicate that the same number of smokers were using that brand in 1988 compared with 1993. 


\begin{tabular}{|c|c|c|c|c|c|}
\hline \multirow[b]{2}{*}{ Community } & \multirow{2}{*}{$\begin{array}{l}\text { Number of } \\
\text { smokers }\end{array}$} & \multicolumn{2}{|c|}{$\begin{array}{l}\text { Brand switching } \\
(\%)\end{array}$} & \multicolumn{2}{|c|}{$\begin{array}{c}\text { Company switching } \\
(\%)\end{array}$} \\
\hline & & Per 5 yeurs & Per year ${ }^{\star}$ & Per 5 years & Per year ${ }^{*}$ \\
\hline Hayward, California & 323 & 34.1 & 8.0 & 30.3 & 7.0 \\
\hline Vallejo, California & 324 & 38.9 & 9.4 & 32.8 & 7.6 \\
\hline Cedar Rapids, Iowa & 415 & 48.9 & 12.6 & 38.5 & 9.3 \\
\hline Davenport, lowa & 413 & 43.6 & 10.8 & 37.7 & 9.0 \\
\hline Lowell, Massachusetts & 327 & 41.9 & 10.3 & 36.4 & 8.7 \\
\hline Fitchburg/Leominster, Massachusetts & 331 & 45.3 & 11.4 & 39.8 & 9.7 \\
\hline Paterson, New Jersey & 253 & 28.9 & 6.6 & 20.2 & 4.4 \\
\hline Trenton, New Jersey & 311 & 29.3 & 6.7 & 25.7 & 5.8 \\
\hline Las Cruces, New Mexico & 387 & 40.3 & 9.8 & 29.9 & 6.9 \\
\hline Santa Fe, New Mexico & 347 & 32.0 & 7.4 & 25.9 & 5.8 \\
\hline Yonkers, New York & 309 & 32.7 & 7.6 & 26.2 & 5.9 \\
\hline New Rochelle, New York & 329 & 26.1 & 5.9 & 19.8 & 4.3 \\
\hline Utica, New York & 377 & 43.2 & 10.7 & 36.4 & 8.7 \\
\hline Binghamton/Johnson City, New York & 375 & 39.2 & 9.5 & 32.1 & 7.5 \\
\hline Greensboro, North Carolina & 388 & 35.8 & 8.5 & 29.1 & 6.6 \\
\hline Raleigh, North Carolina & 383 & 38.9 & 9.4 & 31.4 & 7.3 \\
\hline Medford/Ashland, Oregon & 370 & 46.5 & 11.8 & 41.7 & 10.2 \\
\hline Albany/Corvallis, Oregon & 380 & 50.0 & 12.9 & 42.7 & 10.5 \\
\hline Bellingham, Washington & 355 & 41.7 & 10.2 & 32.8 & 7.6 \\
\hline Longview/Kelso, Washington & 384 & 48.4 & 12.4 & 43.1 & 10.7 \\
\hline & & 39.3 & 9.5 & 32.6 & 7.6 \\
\hline
\end{tabular}

$\star$ Annual rate $=1-\exp (\ln (1-5$ year switch rate $) / 5)$.

Ratios less than 1.0 indicate a loss of market share, whereas ratios greater than 1.0 imply a gain in market share. Given the fact that this study is restricted to adult current smokers, any gain in market share is due to brand switching, whereas losses can be the result of switching away from a brand, quitting smoking, or death.

\section{Company loyalty/switching}

The Maxwell consumer report ${ }^{14}$ and the Directory of cigarette brands published by the Tobacco Merchants Association ${ }^{15}$ were used to identify the parent company for each cigarette brand. Company loyalty was inferred when a smoker reported smoking a cigarette brand manufacturered by the same company in both surveys. Company switching was defined as brand switching when a different parent company was identified for the 1993 brand compared with the brand smoked in 1988 .

ANALYSIS

Estimates of the amount of brand and company switching among cohort members were computed overall and separately by community. Gain/loss ratios were computed for the top 10 selling cigarette brands and generic cigarettes in 1993. Annual rates of switching over the five-year study period were computed assuming a constant rate of switching over time. ${ }^{16}$

To identify characteristics of smokers predictive of brand switching, bivariate and multivariate analyses were performed. Smoker characteristics evaluated in relationship to brand switching included age, gender, education level, average annual household income, amount smoked daily, desire to stop smoking, and attempts made to stop smoking in the past year. Initially, each potential predictor was tested using a $\chi^{2}$ test. A variable was considered significantly associated with brand switching if the probability value was less than 0.05 . A logistic regression analysis was performed to evaluate the simultaneous role of the different significant variables identified from bivariate analyses.

The cigarette industry has consistently argued that cigarette advertising and promotions are intended to affect interbrand competition among adults who already smoke. If this were true, we would expect to observe a decline in unit sales for a given brand if fewer adults report smoking that brand. If, on the other hand, we observe large discrepancies between brand share based on adults and actual unit sales, it might suggest that product marketing is affecting uptake of smoking by younger non-smokers. To evaluate this question, we developed a measure of projected unit sales from our adult cohort data. This measure was computed by first calculating a fraction to represent the percentage of adult fraction to who reported using a given brand in 1993 out of the total number of smokers using that same brand in 1988. This fraction estimates the amount of attrition (or gain from brand switching) associated with a given brand over a five-year period (1988 to 1993). This fraction was then multiplied by actual unit $\delta$ sales in 1988 to obtain a projection of the unit $₹$ sales for 1993 for a given brand based on adult 의 market share. The measure of projected unit sales for a given brand was compared with actual unit sales for that brand in 1993. Data $N$ actual unit sales for thit sales was obtained from the Maxwell consumer reports. ${ }^{14}{ }^{17}$ for 1988 and $~$ 1993.

Results and company switching by community. $T$ Averaged across all 20 communities, we ${ }_{0}$ estimate an annual brand switching rate of $9.5 \%$, and a company switching rate of $7.6 \%$. $\frac{\mathbb{\Phi}}{\mathcal{Q}}$

Table 2 shows characteristics of smokers who switch brands. The results of our logistic regression model reveal that brand switching was more likely to occur among females, nonHispanic whites, persons with lower annuaf? household incomes, heavy smokers, and 
Discrepancies in cigarette brand sales and adult market share

Table 2 Characteristics of smokers associated with brand switching*

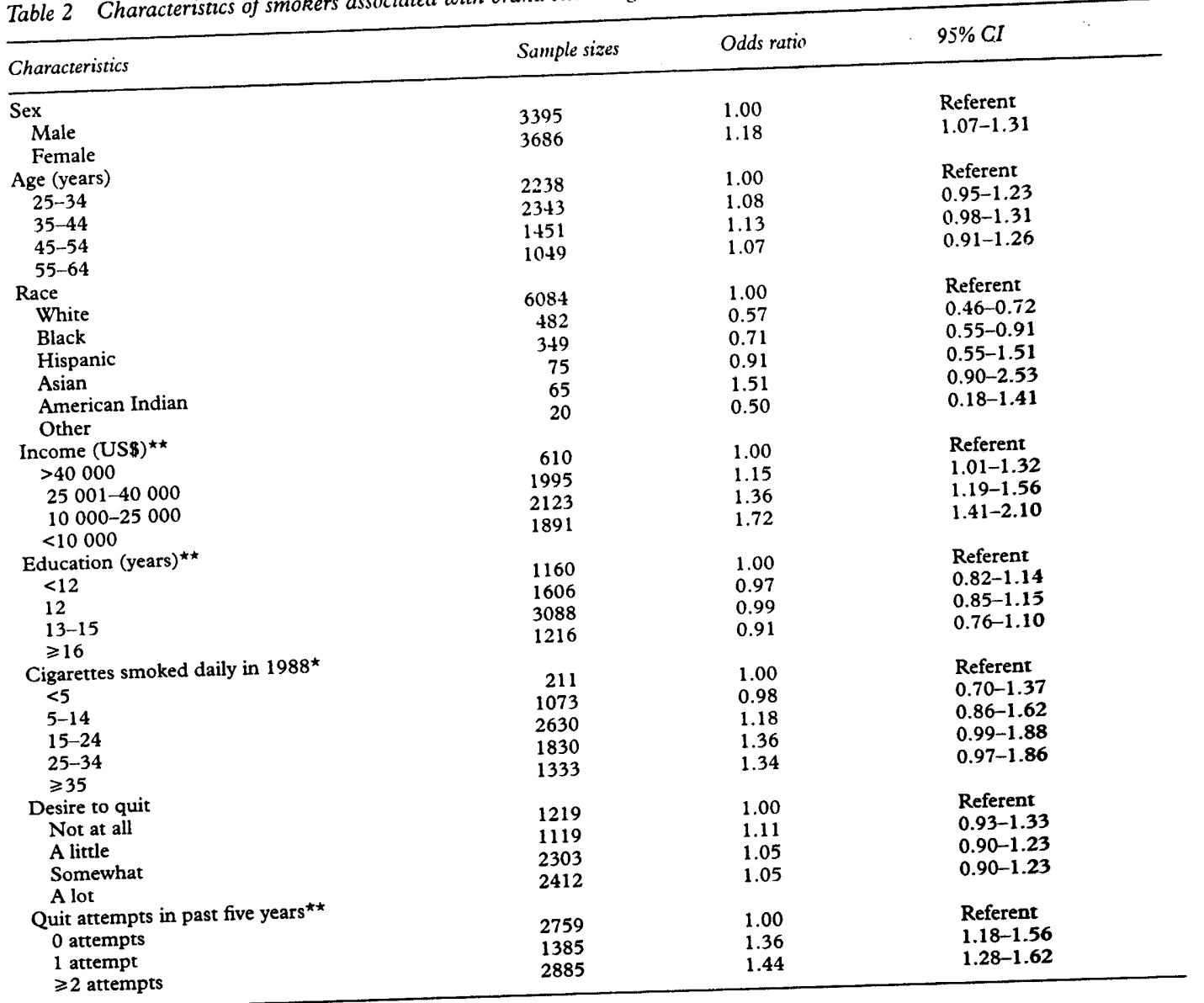

*Controlled for COMMIT intervention.

$\star \star \mathrm{P}<0.05$ for Mantel-Haenszel test for linear association.

$\mathrm{CI}=$ confidence intervals.

among those who had made one or more quit attempts in the past five years.

Figure 1 shows the gain/loss ratios for the 10 top selling cigarette brands in 1993. These 10 brands accounted for $71 \%$ of brands reported by respondents in our 1993 survey. Among the adult smokers tracked in our study, only generic and Doral (a discount brand) cigarettes showed a gain in the number of smokers. Top-selling premium cigarette brands such Marlboro, Winston, Newport, Camel, and Kool all had gain/loss ratios well under 1.0. The loss of smokers to a given brand was due primarily to cessation of smoking. Between 1988 and 1993, we estimate that on an average annual basis the top-selling premium brands (Marlboro, Winston, Camel, Merit, Newport) each lost an average of $12 \%$ of their adult customer base.

Figure 2 shows the discrepancies between projected unit sales based on adult brand share and actual unit sales in 1993 for top selling premium cigarette brands. In general, projected and actual unit sales were similar with the exception of two brands: Marlboro and Camel. For Marlboro, actual sales in 1993 exceeded projected sales by $38 \%$; Camel sales exceeded projected sales by $102 \%$.

\section{Discussion}

The results from this study are consistent with other research which shows that smokers are brand loyal despite the fact that the measure of

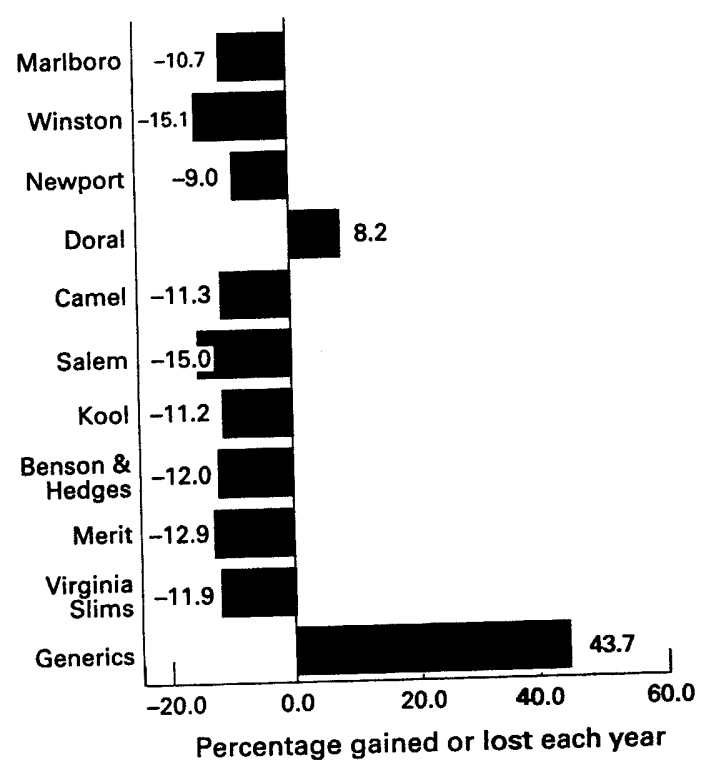

Figure 1 Gain/loss ratios for the top 10 selling cigarette brands in 1993. The figures represent the ammual loss or gain in market share among established smokers berween 1988 and 1993.

brand switching used in this study differs slightly from that used in other research. ${ }^{18} 19$ We estimate that fewer than $10 \%$ of smokers switch brands each year. Although we recognise that this estimate of brand switching may understate the actual rate of switching, as our measure does not account for switching which may have occurred between 1988 and 


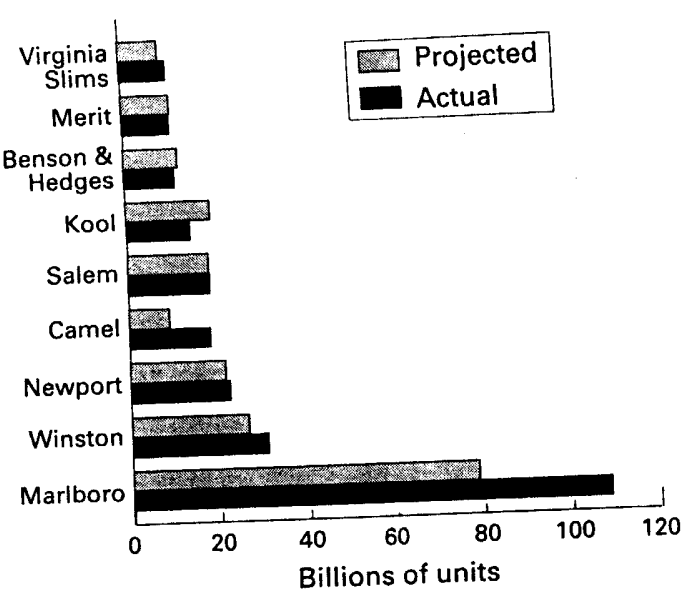

Figure 2 Actual vs projected unit sales for nine of the top-selling premium cigarette brands in 1993.

1993. According to our measure of brand switching, a smoker was defined as brand loyal so long as they reported using the same brand in the final year as they did in the first year.

Most adult smokers in our study continued to smoke a premium brand cigarette. However, our results show that an increasing number of adult smokers were responding to price in deciding which brand of cigarette to smoke. ${ }^{20}$ Brand switching was more common among those smokers who would be expected to be more sensitive to price; namely, those with lower incomes and with higher levels of daily consumption. Consistent with this observation, most of those who switched brands moved from smoking a premium brand to a less costly discount or generic brand. Among smokers in our study, use of generic cigarettes increased six-fold between 1988 and 1993.

With the exception of Doral (a discount brand) all of the top-selling brands we studied declined in unit sales between 1988 and 1993. The decline in unit sales for most brands were consistent with the projected loss due to adult smokers either quitting and/or switching to cheaper discount brands. The two exceptions were Marlboro and Camel where actual unit sales were substantially higher than predicted on the basis of adult market share for these brands. The discrepancy between actual and projected unit sales for Marlboro and Camel is most likely attributed to the popularity of these brands with younger smokers. $^{22}{ }^{23}$

A 1984 strategic research report by RJ Reynolds Tobacco Company entitled Younger adult smokers: strategies and opportunities, concluded that younger smokers (defined as under 25 years of age) have been the critical factor in the growth and decline of every major brand and company over the last 50 years. ${ }^{24}$ The report notes that younger smokers are the only source of replacement smokers for adults who discontinue smoking. The report describes how RJ Reynolds can position itself to compete against other tobacco companies for a share of the young smoker market.

The findings from this study suggest that $\mathrm{RJ}$ Reynolds was successful in its strategy to compete for a share of the young smoker market with its "Joe Camel" cigarette brand. The continuing success of the Marlboro cigarette brand also can be attributed to the popularity of this brand among young smokers. ${ }^{25}$ Without a coninuing stream of new younger smokers, we would have expected that the unit sales for Marlboro and Camel would have declined markedly over the past several years. Although some decline in unit sales was seen for these brands between 1988 and 1993, the decline was much less than predicted based on our estimates of adult market share. Recent sales figures for Marlboro and Camel show that these brands have actually increased domestic sales over past years. ${ }^{26}$ It does not appear to be a coincidence that recent improved sales of Marlboro and Camel brands corresponds with an increase in teenage smoking. ${ }^{27}$

Support for this research has been provided by the Nationa Support for this researt Wood Johnson Foundation. We Cancer lnst the 11 COMMIT research are indebte sites, the COMMr ment Services, Inc., and staft at the National Cancer collection who planned and coordinated

1. US Federal Trade Commission. Feders the Federal Cigarette peport

Trade Commission, 1995 . Br $\mathcal{F}$ Addict $1989 ; 84: 1241-6$.

the teen epidemic. Consumer Reports 1995 Mar: 142-7.

TW, Paulman PM, et al. RJR Nabis-

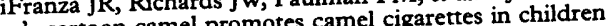
co's cartoon camel promocs.

5 Pollay RW, Levack A. The targeting of youth by cigarette marketers: archival evidence on trial. In: McAlister $\mathrm{L}$, Rothschilds ML, eds. Advances in Consumer Research. Provo, Utah: Association of Consumer Research, 1989; 20:266-71.

6 Warner $\mathrm{K}$ Selling smoking: cigarette advertising and public health. Washington, DC: American Public Health Association, 1986.

7 Lynch BS, Bonnie RJ, eds. Growing up tobacco free: preventing nicotine addiction in children and youths. Washington, DC:

National Academy Press, Institute of Medicine, 1994. 16

8 Boddewyn JJ. Fuvenile smoking initiation and advertising: a 16 country study of the perceived role of advertising and other faccors bearing on juvenile smoking initiation. New International Advertising Association, 198 . Dubow JS. A Cam:

10 COMMIT Research Group. Community Intervention Trial for Smoking Cessation (COMMIT): summary of design and intervention. 7 Natl Cancer Inst 1991;83:1620-8.

11 and intervention. $\mathcal{F}$ Natl Cancer Inst $\mathrm{KM}$, Lynn WR, et al. Evaluation plan for the community intervention trial for smoking cessation (COMMIT). Int $Q$ Commun Health Educ 1991; 11:271-90.

12 COMMIT Research Group. Community Intervention Trial for Smoking Cessation (COMMIT). I. Cohort results for Smoking Cessation unity intervention. Am $f$ Public from a four-year comm.

Health 1995;85:183-92. form for Smoking Cessation (COMM Am ₹ Public Health 1995; 85:193-200.

14 Maxwell JC Jr. The Maxwell consumer report. Fourth-quarter and year-end 1993 sales estimates for the cigarette industry. Richmond, VA: Wheat First Securities, 10 February 1994.

15 Delman F, Marisan AM Jr, Umana J, Sukhra KJ, eds. Directory of cigarette brands, 1964-1988. Princeton, New Jersey: Tobacco Merchants Association of the United States, 31 August 1989.

16 Johnson RA, Bhattacharyya GK. Statistics: principles and methods, 2nd ed. New York: John Wiley \& Sons, 1992.

17 Maxwell JC, Jr. The Maxwell consumer report: Year end 1988 sales estimates for the cigarette industry. Richr.

18 Gardner T. Under siege, cigarette marketers fight back. Marketing and Media Decision 1984;19:34-40.

19 Siegel M, Nelson DE, Peddicord JP, et al. The extent of cigarette brand and company switching: results from the ad

20 Zimmerman C. Price value: how discount cigarettes captured 40 percent share. Tobacco Reporter 1993 Mar:54

21 Cavin SW, Pierce JP. Low cost cigarettes and smoking Crev Med 1996; 12:17-21.

22 US Centers for Disease Control. Comparison of the cigarette brand preferences of adult and teenaged

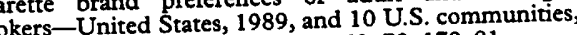
1988 and 1990. MMWR 1992;41:169-73, 179-81. 
23 US Centers for Disease Controt changes in cigarctte brand United States, 1989 1992 MIIIVR 1994;43:577 81.

4 Burrows DS (RI Reynolds Tobacco (ompany). MemoranBurrow DS (R Ro, Orlowskv, HJ lees.

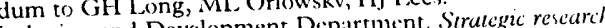

25 Marketing and Development Depalcies and opporturitic:
Winston-Salem, North Carolina: RJ Reynolds Tobacco Company, 29 February 1984

26. Int 1996 October:43 7 .

7 Sormanczy M. The premium story. Tobacco Reporter 1996

November: $18 \cdots 20$.

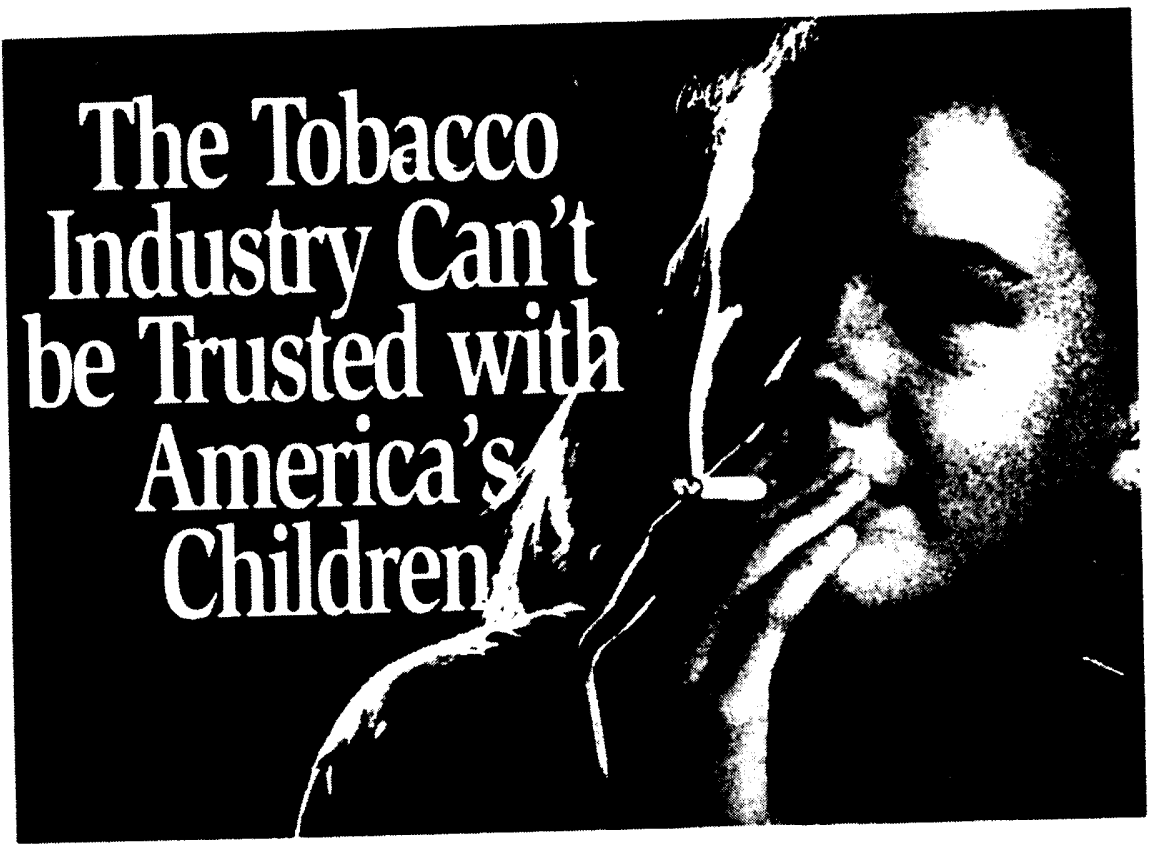

They say there is no proof that smoking and smokeless tobacco cause disease and death.

They claim nicotine

Do you believe them? 3,000 children begin smoking every day, and the rate is increasing, especially among younger kids. Almost all of them smoke one of the three most heavily advertised brands. One third will eventually die of their addiction.

President Clinton and the Food \& Drug Administration, joined by many members of CongressRepublicans and Democrats - have proposed new isn't addictive. limits on sales and marketing of tobacco to children.

They swear they

Please give your support. Write to the FDA. Dockets Management Branch. Docket 95N-0253, Room don't market to kids.

They claim to be taking care of the problem of underage tobacco use.

1-23, 12420 Parklawn Drive, Rockville, MD 20857.

Don't trust the tobacco industry to do the right thing. They never have. They never will.

This ad sponsored by the American Cancer Society, the American Academy of Pediatrics, the American Heart Association, the American Lung Association. the American Medical Association and over 100 other organizations that support the Campaign for Tobacco-Free Kids.

For additional information, or to contribute to more ads like this: 1-800-284-KIDS. 